\title{
Students' views of patient led teaching
}

Author: Victoria Tavares. Manchester Pharmacy School, The University of Manchester

Background: The involvement of patients in the education and training of health professionals is considered essential for the delivery of patient centred services. ${ }^{1}$ This view is reflected by the General Pharmaceutical Council who suggest using patients in class. ${ }^{2}$ There are few studies that describe experiences of involving patients in the teaching of pharmacy undergraduates, however literature relating to other healthcare professions suggests that teaching by patients impacts on students' communication skills, promotes learning about the patients' perspective and increases confidence. ${ }^{3}$

Method: A school of pharmacy worked with Self Management UK to deliver patient led teaching sessions to $1^{\text {st }}$ year pharmacy undergraduate students in their first semester (October 2013). Between three and five patients worked with groups of twenty students with the aim of increasing students' understanding of living with a long term condition. A focus group was carried out after the sessions to explore student reactions and learning. It was audio recorded, transcribed and subjected to a thematic analysis.

Results: Students described learning in relation to understanding a patient's perspective. Development of empathy, understanding reasons for non-adherence and insights into how patients deal with illness were reported. Students reported a lack of confidence when asking questions during the sessions; reasons provided included group size (when working as twenty) and a fear of offending the patient. Students provided a number of suggestions to improve the sessions, which included reducing the group size, increasing time spent talking with the patients and managing students' expectations.

Conclusion: Implementation of the improvements suggested by the students may encourage participation of those students who felt less confident. Introducing patient led teaching sessions with $1^{\text {st }}$ year pharmacy students early in their training may help them understand patients' perspectives. This provides a grounding which can be spiralled upon throughout their studies to help develop a patient centred approach to their work.

\section{References}

1. Joint Health and Social Care Regulators' Patient and Public Involvement Group. A PPI Good Practice Handbook for UK Health Care Regulators. October 2010. Available at: http://www.hpcuk.org/assets/documents/100032B6A_PPI_Good_Practice_Handbook_for_UK_Health_Care_Regulat ors.pdf

2. General Pharmaceutical Council. Future Pharmacists Standards for the initial education and training of pharmacists. May 2011. Available at: http://www.pharmacyregulation.org/initialtraining

3. Morgan A, Jones D. Perceptions of service user and carer involvement in healthcare education and impact on students' knowledge and practice: A literature review. Medical Teacher. 2009; 31: 82-95 